\title{
Patterns of tobacco and e-cigarette use status in India: a cross-sectional survey of 3000 vapers in eight Indian cities
}

\author{
Rajeshwar Nath Sharan ${ }^{1 *}$, Tongbram Malemnganbi Chanu', Tapan Kumar Chakrabarty ${ }^{2}$ and \\ Konstantinos Farsalinos ${ }^{3,4,5}$
}

\begin{abstract}
Background: Tobacco smoking is one of the biggest and avoidable public health threats in the world, especially in low- and middle-income countries. India represents a highly complex public health environment due to the large number of smokers and complexities arising from tobacco use in different forms, including a variety of smokeless tobacco (SLT) products. Electronic cigarettes, an alternative nicotine delivery system with significantly less harmful emissions than smoke, could be an option for those who are unable to achieve smoking abstinence using other available means. This study, which we believe is the first of this kind in India, was conducted to obtain data on the characteristics and tobacco use profile of e-cigarette users (vapers) in India.

Methods: An interview-based survey was performed in the 8 largest metropolitan cities in India using a convenience sampling approach involving a total of 3000 subjects. Inclusion criteria were being a current ecigarette user and aged 18 years or more. Interviewers were asked to continue recruitment until a total sample of 375 was reached in each target city.

Results: A total of 3000 vapers ( $81.4 \%$ males and $18.6 \%$ females, median age 29 years) participated to the study. The majority (80\%) were first exposed to nicotine via tobacco smoking, SLT use, or both. Most of the subjects (79\%) believed that e-cigarettes were less harmful than smoking. The vast majority of smokers (71.3\%) reported smoking cessation (30.0\%) or reduction in consumption (41.3\%) with the help of e-cigarettes. Similar changes were observed in SLT users. Participants reported minimal side effects and some health benefits after e-cigarette use initiation.

Conclusion: Indian vapers who participated to this study were predominantly smokers and SLT users before ecigarette use initiation, with the majority subsequently quitting or reducing tobacco use. Minimal side effects of ecigarette were experienced, while some health benefits were also reported.
\end{abstract}

Keywords: Tobacco smoking, E-cigarette, Nicotine, Vaping, Tobacco cessation

\footnotetext{
* Correspondence: rnsharan@nehu.ac.in

'Radiation \& Molecular Biology Unit, Department of Biochemistry, North-Eastern Hill University, Shillong 793022, India

Full list of author information is available at the end of the article
}

(c) The Author(s). 2020 Open Access This article is licensed under a Creative Commons Attribution 4.0 International License, which permits use, sharing, adaptation, distribution and reproduction in any medium or format, as long as you give appropriate credit to the original author(s) and the source, provide a link to the Creative Commons licence, and indicate if changes were made. The images or other third party material in this article are included in the article's Creative Commons licence, unless indicated otherwise in a credit line to the material. If material is not included in the article's Creative Commons licence and your intended use is not permitted by statutory regulation or exceeds the permitted use, you will need to obtain permission directly from the copyright holder. To view a copy of this licence, visit http://creativecommons.org/licenses/by/4.0/ The Creative Commons Public Domain Dedication waiver (http://creativecommons.org/publicdomain/zero/1.0/) applies to the data made available in this article, unless otherwise stated in a credit line to the data. 


\section{Introduction}

Tobacco smoking is one of the biggest preventable causes of non-communicable disease affecting both users and bystanders $[1,2]$. The World Health Organization (WHO) estimates that there are more than 1.1 billion smokers globally and predicts 1 billion premature smoking-related deaths during the twenty-first century. Approximately, $80 \%$ of these deaths are likely to occur in the low- and middle-income countries (LMICs) where the prevalence of smoking is particularly high and growing [2]. India, the world's fastest growing large economy in 2018 , is the home to over $11 \%$ of the world's cigarette smokers but also has a significantly larger proportion of the population indulging in (a) smoking tobacco in its alternative or local forms (e.g., bidis, hookah, chilam, shisha, water pipes), (b) chewing or masticating smokeless tobacco (SLT) in various forms, e.g., khaini, zarda, gutkha, and paan masala in combination with or without betel (Areca) nut, or (c) a combination of the two (mixed users). Therefore, India represents a complex public health challenge [3]. Tobacco-related deaths in India are estimated to be over 1 million/year [4] and are projected to rise to 1.5 million by 2020 [5]. Global Adult Tobacco Survey (GATS) data of 2016-2017 shows that India has the second largest tobacco consuming population in the world, estimated to be over 267 million, which includes at least 100 million tobacco smokers and over 199 million SLT users [6]. While smoking tobacco in different forms, including cigarettes, is predominantly found among men, SLT usage is more widespread among women [6].

The impact of smoking and harmful SLT use in India is evident from data on disease burden in the Indian population [7]. While ischemic heart disease and chronic pulmonary obstructive disease, diseases that are etiologically linked to smoking $[8,9]$ were ranked 6th and 8 th, respectively; in disease burden in India during the 1990s, they were in the first two positions in 2016 [7]. Therefore, reducing the prevalence of smoking and other harmful tobacco product use is expected to have a substantial public health impact in India. However, the country faces substantial challenges related to the lack of adequate facilities to support smoking cessation [10], limited recruitment and success among smokers [11], and limited motivation and experience of healthcare professionals to provide smoking cessation support [12, 13].

A relatively recent technological development is the invention of electronic cigarettes (e-cigarettes), products that can deliver nicotine without combustion. These can be used as a harm reduction tool and appear to be a viable option for those who are unable to quit smoking using other available means [1, 14]. E-cigarettes have undergone significant refinements and improvements from the first generation devices of early 2005 to the currently available third and fourth generation improved devices offering better performance [15-19].

The entry of e-cigarettes to the Indian market triggered debate among users, clinicians, scientists, public health professionals, policy makers, and other stakeholders on the pros and cons of e-cigarette use as an additional tool to achieve better tobacco control. Ecigarettes are currently being used by only a very small proportion of Indians. The 2015 GATS- 2 estimated that the prevalence of use was $0.02 \%$ (268,000 users) [6]. The Indian Council of Medical Research has expressed substantial concerns about e-cigarettes and recommended a complete prohibition of e-cigarettes to protect public health [20]. While there has been some criticism that the report was unbalanced and failed to consider the totality of the evidence [21], the Indian government decided to implement a total ban on the import and sale of these products. Unfortunately, these decisions were made without previously examining the patterns of ecigarettes use in India and the profile, smoking status, and perceived benefits or harms among local users. To better understand such parameters, we performed the first, to the best of our knowledge, cross-sectional survey among e-cigarette users (vapers) in India.

\section{Methods}

Since e-cigarette use was low in India, it was not feasible to recruit vapers using a probability-based random sampling approach. There were also no suitable sampling frames in India (e.g., membership lists) from which to select subjects. Many surveys of vapers have relied on self-volunteered internet samples, but these also face various limitations (lack of control over recruitment location, possibility for double entries, confirmation of respondent's fit into the inclusion criteria, indeterminate reliability and validity, etc.). In this study, we aimed to generate a sample of current vapers in India in order to obtain information on their experience with e-cigarette use and examine their past and current smoking status. Therefore, and in light of the limitations of sampling avenues, we decided to recruit a convenience sample of e-cigarette users from across India, in order to reduce bias due to recruitment in one location. We chose the 8 largest metropolitan areas of India, namely Delhi in northern, Kolkata in the eastern, Ahmedabad, Mumbai, and Pune in western, and Bangalore, Chennai, and Hyderabad in the southern regions of India (Fig. 1). We decided on an overall sample size of 3000 in order to increase the power to conduct analysis of subgroups (e.g., gender, prevalence, and health). This was a convenience sample in which interviewers in these target cities were asked to identify vapers from among their contacts and networks. Inclusion criteria were being a current ecigarette user (based on self-report) and aged $\geq 18$ years. 


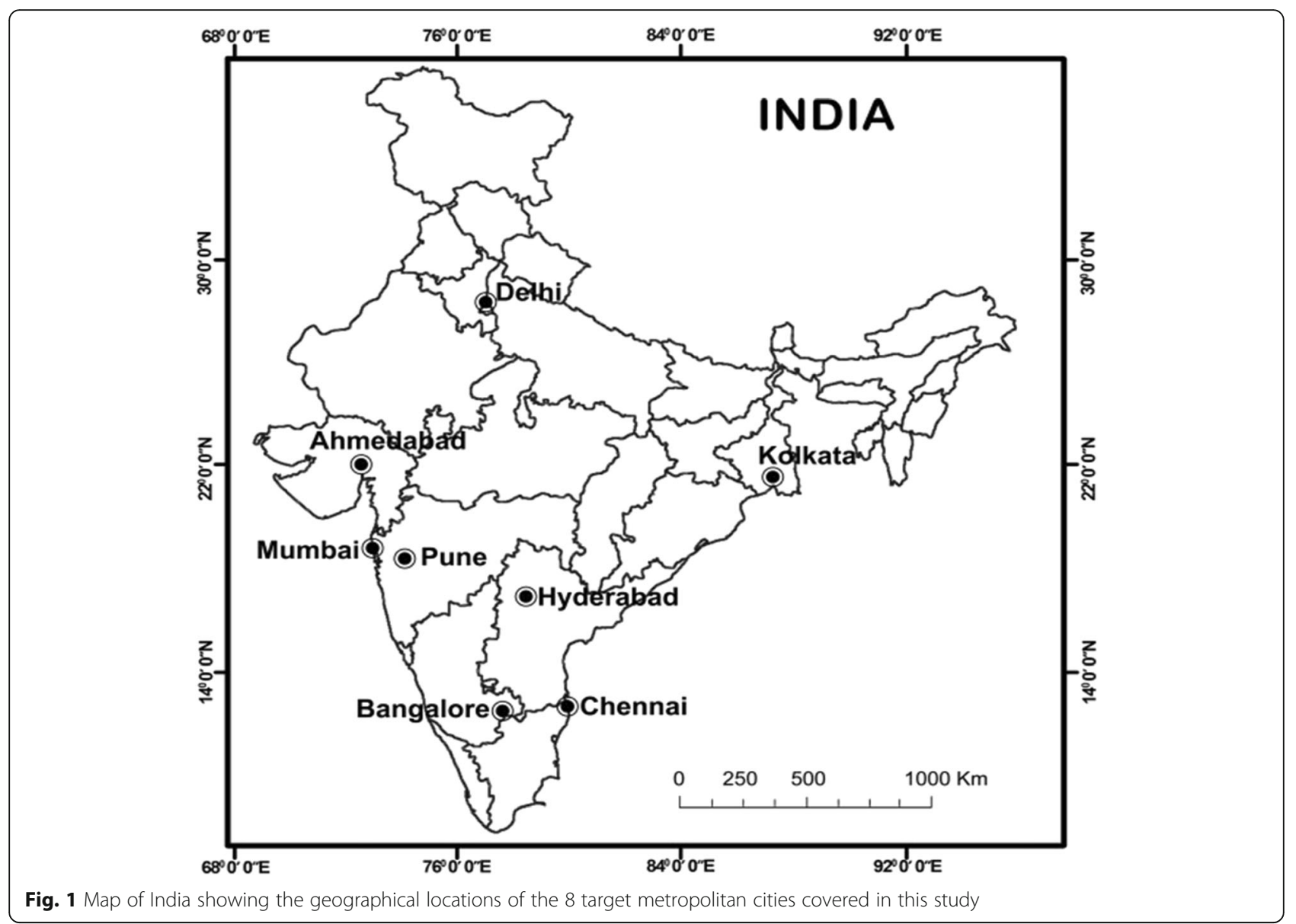

Interviewers were asked to continue recruitment until a total sample of 375 was reached in each target city.

A questionnaire comprising 72 questions was used for the survey, which was based on previous online surveys $[22,23]$. To improve the questionnaire design and ensure the comprehension of the survey items, 7 ecigarette users (who did not participate to the final study sample) were recruited and participated in an assessment of the questionnaire using the method of cognitive interviewing [24]. The first part of the questionnaire included demographic data. Subsequently, participants were asked about their past (before e-cigarette use initiation) and current smoking and SLT use patterns, including duration and frequency of use. Assessment of smoking dependence was performed by using the Fagerström Test for Cigarette Dependence (FTCD) [25]. Then, there were questions about patterns of current e-cigarette use, including frequency of use, types of products used, and daily consumption. Additionally, participants were asked to report self-perceived changes in health parameters as well as side effects after e-cigarette use initiation, based on a previous survey [22]. The selfreported effect of e-cigarettes on tobacco use status of study participants was assessed separately for smoking tobacco and for SLT use by asking "Did you manage to reduce or quit smoking tobacco with the help of ecigarettes?" and "Did you manage to reduce or quit chewing (oral) tobacco with the help of e-cigarette?" Response options were (1) Yes, I managed to quit; (2) Yes, I managed to reduce consumption; (3) Initially, I managed to quit but then I relapsed; (4) No, I did not quit or reduce consumption; and (5) No and in fact I increased my consumption. Finally, the perception of harm from e-cigarette was examined both in absolute terms and in comparison to smoking by asking "Do you think e-cigarettes are (1) Absolutely harmless, (2) Substantially less harmful than tobacco cigarettes, (3) Slightly less harmful than tobacco cigarettes, (4) Equally harmful as tobacco cigarettes, 5. Slightly more harmful than tobacco cigarettes, and (6) Substantially more harmful than tobacco cigarettes."

The questionnaire was loaded on handheld devices, laptops, or PCs and was pre-tested before its application in the field. Interviews were conducted either face-toface using the handheld devices or laptops, or in CATI (computer-assisted-telephone-interview) mode. Fieldlevel data were aggregated and perused weekly for quality checks. 
The study was carried out as per the guidelines approved by the Institutional Ethics Committee for Human Samples/Participants (IECHSP) of NEHU. The study was approved on August 02, 2017.

\section{Statistical analysis}

Descriptive analysis was performed, with continuous variables reported as median (interquartile range [IQR]) and categorical variables reported as number (percentage). Non parametric tests (McNemar test) were used to compare smoking and SLT use prevalence between the time before e-cigarette use initiation and the time of the survey while smoking consumption was compared between these two time-points using Wilcoxon signed rank test. Binary logistic regression analysis was performed to examine correlates of having quit smoking. The dependent variable was being a former (rather than a current) smoker, and independent variables were age, gender, education level, smoking duration and consumption, FTCD, e-cigarette use duration, frequency of ecigarette use, liquid consumption, nicotine concentration used, number of different flavors used (one vs. two or more), type of flavors used (tobacco/mint/menthol only vs. at least one non-tobacco/mint/menthol flavor), and perceptions of e-cigarette harmfulness (equally/more harmful than smoking vs. harmless/less harmful than smoking). All data were analyzed using the SPSS ver. 22.0 software.

\section{Results}

\section{Participant characteristics and tobacco use before e-} cigarette use initiation

A total of 3000 respondents were recruited in equal numbers $(n=375)$ from each of the 8 metropolitan cities. The demographics characteristics and history of tobacco use before e-cigarette use initiation of the study participants are presented in Table 1 . The majority of the study sample $(81.4 \%)$ was men. The median age of the respondents was 27 years for women and 30 years for men. Most of them were educated at graduate level or higher. Most participants (71.4\%) had their first exposure to nicotine through combustible tobacco and 9.5\% through SLT. Of the remaining 19.1\% respondents, $1.6 \%$ reported having their first exposure to nicotine through pharmaceutical products and $17.5 \%$ through ecigarettes. Most participants reported smoking tobacco before e-cigarette use initiation, and they had low to moderate cigarette dependence as assessed by FTCD. A small proportion of participants were SLT users before e-cigarette use initiation. However, the vast majority of these subjects were also smoking tobacco; only $1.5 \%$ of SLT users $(n=6)$ reported not smoking tobacco.
Table 1 Participant demographics and tobacco use before ecigarette use initiation

\begin{tabular}{|c|c|}
\hline & $n(\%)$ or median (IQR) \\
\hline Participants & $3000(100)$ \\
\hline \multicolumn{2}{|l|}{ Residence } \\
\hline Eastern India & $375(12.5)$ \\
\hline Western India & $1125(37.5)$ \\
\hline Northern India & $375(12.5)$ \\
\hline Southern India & $1125(37.5)$ \\
\hline Age (years) & $29(25-35)$ \\
\hline \multicolumn{2}{|l|}{ Gender } \\
\hline Male & $2443(81.4)$ \\
\hline Female & $557(18.6)$ \\
\hline Education & 19,269 \\
\hline Less than Senior School Certificate & $6(0.2)$ \\
\hline Secondary/High School Certificate & $340(11.3)$ \\
\hline Graduate/postgraduate & $1874(62.5)$ \\
\hline Professional degree & $780(26.0)$ \\
\hline \multicolumn{2}{|l|}{ First nicotine product ever tried } \\
\hline Combustible tobacco ${ }^{1}$ & $2143(71.4)$ \\
\hline Chewing (oral) tobacco & $284(9.5)$ \\
\hline Pharmaceutical nicotine product & $49(1.6)$ \\
\hline E-cigarette & $524(17.5)$ \\
\hline Smoking before e-cigarette use initiation & $2350(78.3)$ \\
\hline Boxed or roll-your-own cigarettes & $2002(66.7)$ \\
\hline Beedies & $33(1.1)$ \\
\hline Both & $315(10.5)$ \\
\hline Smoking duration (months) & $72(50-108)$ \\
\hline $\begin{array}{l}\text { Daily smoking consumption before e-cigarette } \\
\text { use initiation }\end{array}$ & $8(6-10)$ \\
\hline FTCD before e-cigarette use initiation & $4(3-5)$ \\
\hline SLT use before e-cigarette use initiation & $396(13.2)$ \\
\hline Duration of SLT use & $60(37-93)$ \\
\hline SLT consumption (times per day) & $5(4-7)$ \\
\hline SLT users who also smoked tobacco & $390(98.5)$ \\
\hline
\end{tabular}

${ }^{1}$ The question defined combustible tobacco as "Cigarettes, Cigarillos, Beedies, Hukka/Pipe/Shisha, Cigar, etc."

FTCD Fagerstrom Test for Cigarette Dependence, SLT smokeless tobacco

\section{Current tobacco use patterns}

Current tobacco use patterns of study participants are presented in Table 2. More than half of all participants were still smoking tobacco, but smoking prevalence was reduced from $78.3 \%$ before e-cigarette use initiation to $58.4 \%$ at the time of the survey (McNemar test $P<$ 0.001 ); $30 \%$ of those who reported smoking tobacco before e-cigarette use initiation had quit after e-cigarette use initiation (former smokers). Daily tobacco cigarette consumption was reduced among those who continued to smoke from $8(5-10)$ to 5 (4-8) cigarettes per day 
Table 2 Current tobacco use patterns of study participants

\begin{tabular}{ll}
\hline & $n(\%)$ or median (IQR) \\
\hline Current smoking tobacco & \\
$\quad$ Yes & $1751(58.4)$ \\
No & $1249(41.6)$ \\
Current daily smoking consumption & $5(4-8)$ \\
Former smokers $^{1}$ & $706(30.0)$ \\
Current SLT use $_{\text {Current SLT consumption (numbers per day) }}$ & $538(17.9)$ \\
Current SLT users who also smoke tobacco & $382(71.0)$ \\
\hline
\end{tabular}

${ }^{1}$ Former smokers were defined as those who were smoking tobacco before ecigarette use initiation but were not currently smoking. Proportion of those who reported smoking tobacco before e-cigarette use initiation is presented

(Wilcoxon signed rank test $P<0.001$ ). Current SLT use was reported by $17.9 \%$ of participants, higher than before e-cigarette use initiation (McNemar test $P<0.001$ ). However, $71.0 \%$ of current SLT users reported also smoking tobacco, compared to $98.5 \%$ before e-cigarette use initiation (McNemar test $P<0.001)$.

\section{Patterns of e-cigarette use}

The e-cigarette use patterns of the study population are presented in Table 3. A major source of information about e-cigarettes was family/friends and the internet. On average, the study population was using e-cigarettes for 20 months, with almost half reporting daily use. The majority initiated e-cigarette use with first generation devices and prefilled cartomizers. While these types of products remained popular at the time of the survey, a substantial proportion was also using third generation devices and tank-system atomizers. Refillable bottles and prefilled atomizers were the most popular container type for liquid products used. Tobacco and mint flavors were the most prevalent choices at e-cigarette use initiation; while still popular, a substantial proportion was using fruit, sweet, and nut flavors at the time of the survey. Almost $60 \%$ of participants were using at least one nontobacco/menthol flavor, and most were using at least 2 different types of flavors regularly. E-cigarettes were purchased mostly online and from street shops.

\section{Self-reported effect of e-cigarettes on tobacco use status}

Table 4 displays participant's self-reported effects of e-cigarette use on tobacco use status. Smoking cessation was reported by almost a third of smoking participants, while smoking reduction was reported by an additional $41.3 \%$. Some reported initially quitting but subsequently relapsing back to smoking, while a small minority reported increased smoking consumption after e-cigarette use initiation. Similar findings were observed among SLT users. More than one third of SLT users reported quitting, while an additional 30\% reported a reduction in consumption. Again, a small minority reported an increase in SLT consumption after e-cigarette use initiation.

\section{Health effects of use and harm perceptions}

Approximately, one third of participants reported at least one adverse symptom that they attributed to ecigarette use (Table 5). The commonest side effect was cough, followed by headache and dry mouth/throat. More than $90 \%$ reported complete or partial resolution of the symptoms over time. More than half of participants reported improvements in their general health, breathing, olfactory and gustatory senses, and breathing after initiation of e-cigarette use (Table 6).

Participants' perception of harm about e-cigarettes is presented in Fig. 2. A vast majority considered ecigarettes substantially or slightly less harmful than smoking. Less than 1 out of 10 participants considered e-cigarettes absolutely harmless while more than $20 \%$ considered them equally or more harmful than smoking.

\section{Correlates of having quit smoking}

The results of the logistic regression analysis are presented in Table 7. Males had lower odds of having quit smoking compared to females, while higher FTCD was negatively associated with being a former smoker. Ecigarette use frequency, liquid consumption, higher nicotine concentration and perceived lower harmfulness of e-cigarettes compared to tobacco cigarettes were positively associated with being a former smoker.

\section{Discussion}

To the best of our knowledge, this is the first study to examine the characteristics of vapers in India. Participants were mostly smokers and SLT users, in agreement with other studies of adult populations showing that ecigarette use is predominantly observed among current or former smokers [22, 26, 27]. The main results of this survey indicate that e-cigarettes could potentially be an effective partial or complete substitute for tobacco use for some smokers and SLT users in India. While this should be considered in the context of limited smoking cessation interventions in India, the government has recently decided to ban these products.

A substantial proportion of the study population experienced benefits in terms of reduction or quitting smoking. A similar proportion reported smoking reduction and cessation in the Eurobarometer study, although that was a population-representative sample [27]. Frequent ecigarette use was one of strongest correlates of being a former smoker. This is expected, considering that experimental or occasional use of any smoking cessation aid is unlikely to be substantially effective. Frequent ecigarette use could indicate motivation and intention to 
Table 3 E-cigarette use patterns of study participants

\begin{tabular}{ll}
\hline & $n(\%)$ or median \\
$(\mathrm{IQR})$
\end{tabular}

Where did you first hear about e-cigarettes

Internet

$1836(61.2)$

E-cigarette users' forums

$720(24.0)$

Family/friends

Shops selling e-cigarettes (physical or online)

TV/radio/newspapers

Healthcare professionals

Do not remember

E-cigarette duration of use

E-cigarette frequency of use

Daily

Weekly

Monthly

Less than monthly

E-cigarette device used now

1st generation (cigarette-like)

2nd generation (eGo style)

3rd generation (mechanical mods or variable voltage/wattage devices)

Do not know

E-cigarette atomizers used now

Prefilled cartomizers

Refillable cartomizers

Tank systems with ready to use atomizer heads

Tank systems or drippers with rebuildable coils and wicks

Do not know

E-cigarette device first bought

1st generation (cigarette-like)

2nd generation (eGo style)

3rd generation (mechanical mods or variable voltage/wattage devices)

Do not know

E-cigarette atomizer first bought

Prefilled cartomizers

Refillable cartomizers

Tank systems with ready to use atomizer heads

Tank systems or drippers with rebuildable coils and wicks

Do not know

In which form do you buy liquids

Prefilled cartridges

Bottles with ready-to-use liquids

Liquid base and flavorings (do-it-yourself)
Table 3 E-cigarette use patterns of study participants (Continued)

\begin{tabular}{|c|c|}
\hline & $\begin{array}{l}n(\%) \text { or median } \\
\text { (IQR) }\end{array}$ \\
\hline Daily liquid consumption & $5(3-6)$ \\
\hline Nicotine concentration in liquids & $3(3-6)$ \\
\hline Use of non-nicotine liquids & $602(20.1)$ \\
\hline \multicolumn{2}{|l|}{ Flavors used now } \\
\hline Tobacco & $1887(62.9)$ \\
\hline Mint/menthol & $1797(59.9)$ \\
\hline Sweet & $618(20.6)$ \\
\hline Nuts & $674(22.5)$ \\
\hline Fruits & $1152(38.4)$ \\
\hline Drinks and beverages & $369(13.2)$ \\
\hline Other & $9(0.3)$ \\
\hline Do not remember & $8(0.3)$ \\
\hline Use of at least one non-tobacco/mint flavor & $1780(59.3)$ \\
\hline \multicolumn{2}{|l|}{ Flavors used at e-cigarette use initiation } \\
\hline Tobacco & $1674(55.8)$ \\
\hline Mint/menthol & $1272(42.4)$ \\
\hline Sweet & $344(11.5)$ \\
\hline Nuts & $345(11.5)$ \\
\hline Fruits & $776(25.9)$ \\
\hline Drinks and beverages & $202(6.7)$ \\
\hline Other & $0(0.0)$ \\
\hline Do not remember & $10(0.3)$ \\
\hline \multicolumn{2}{|l|}{ Number of different flavors used regularly now } \\
\hline 1 & $1034(34.5)$ \\
\hline 2 & $1511(50.4)$ \\
\hline 3 & $337(11.2)$ \\
\hline 4 & $94(3.1)$ \\
\hline 5 & $13(0.4)$ \\
\hline$>5$ & $11(0.4)$ \\
\hline \multicolumn{2}{|l|}{ Source of e-cigarette purchase } \\
\hline Online & $1712(57.1)$ \\
\hline Department stores & $1061(35.4)$ \\
\hline Pharmacies & $243(8.1)$ \\
\hline Street shops & $1580(52.7)$ \\
\hline Abroad & $846(28.2)$ \\
\hline Other & $33(1.1)$ \\
\hline
\end{tabular}

use them as smoking cessation aids or could be the result of completely substituting for smoking. In any case, our findings are in agreement with several studies showing that frequent e-cigarette use is associated with smoking cessation [28-31]. Higher nicotine concentrations were also positively associated with being a former smoker. Nicotine use with e-cigarettes is important in 
Table 4 Self-reported effects of e-cigarettes on tobacco use status of study participants

\begin{tabular}{ll}
\hline & $n(\%)$ \\
\hline Qmoking status ( $n=2350)$ & \\
Quit smoking & $9706(30.0)$ \\
Reduce smoking consumption & $314(13.4)$ \\
Quit but then relapsed & $311(13.2)$ \\
No reduction in smoking consumption & $49(2.1)$ \\
Increase in smoking consumption & \\
SLT use status ( $n=680)$ & $264(38.8)$ \\
Quit SLT use & $204(30.0)$ \\
Reduce SLT consumption & $149(21.9)$ \\
Quit but then relapsed & $61(9.0)$ \\
No reduction in SLT consumption & $2(0.3)$ \\
Increase in SLT consumption
\end{tabular}

Table 5 Side effects reported by study participants after ecigarette use initiation

\begin{tabular}{|c|c|}
\hline & $n(\%)$ \\
\hline Side effects & Total \\
\hline Sore or dry mouth and throat & $185(6.2)$ \\
\hline Headache & $261(8.7)$ \\
\hline Gingivitis/gum bleeding & $31(1.0)$ \\
\hline Dental problems & $48(1.6)$ \\
\hline Mouth or tongue sores/inflammation & $43(1.4)$ \\
\hline Black tongue & $51(1.7)$ \\
\hline Nose bleeding & $35(1.2)$ \\
\hline Cough & $540(18.0)$ \\
\hline Bowel problems (diarrhea/constipation/pain) & $5(0.2)$ \\
\hline Muscle cramps & $22(0.7)$ \\
\hline Dizziness & $88(2.9)$ \\
\hline Sleepiness & $73(2.4)$ \\
\hline Sleeplessness & $24(0.8)$ \\
\hline Heart palpitations & $11(0.4)$ \\
\hline Breathing difficulties & $57(1.9)$ \\
\hline Allergic reactions & $23(0.8)$ \\
\hline Chest pain & $119(4.0)$ \\
\hline Loss of appetite & $15(0.5)$ \\
\hline No side effects & $2004(66.8)$ \\
\hline \multicolumn{2}{|c|}{ Did the above-mentioned symptoms resolve over time? ${ }^{1}$} \\
\hline Completely resolved & $426(42.8)$ \\
\hline Partially resolved & $501(50.3)$ \\
\hline Completely unresolved & $69(6.9)$ \\
\hline
\end{tabular}

Proportion of those reporting any side effect
Table 6 Changes in health status reported by study participants after e-cigarette use initiation

\begin{tabular}{|c|c|}
\hline & $n(\%)$ \\
\hline \multicolumn{2}{|c|}{ After initiating EC use, have you experienced any changes in: } \\
\hline \multicolumn{2}{|c|}{ Health status in general } \\
\hline Worse & $181(6.0)$ \\
\hline No change & $1058(35.3)$ \\
\hline Better & $1761(58.7)$ \\
\hline \multicolumn{2}{|l|}{ Smell } \\
\hline Worse & $177(5.9)$ \\
\hline No change & $978(32.6)$ \\
\hline Better & $1845(61.5)$ \\
\hline \multicolumn{2}{|l|}{ Taste } \\
\hline Worse & $111(3.7)$ \\
\hline No change & $1095(36.5)$ \\
\hline Better & $1794(59.8)$ \\
\hline \multicolumn{2}{|l|}{ Breathing } \\
\hline Worse & $144(4.8)$ \\
\hline No change & $1346(44.9)$ \\
\hline Better & $1510(50.3)$ \\
\hline \multicolumn{2}{|l|}{ Appetite } \\
\hline Worse & $173(5.8)$ \\
\hline No change & $1747(58.2)$ \\
\hline Better & $1080(36.0)$ \\
\hline \multicolumn{2}{|c|}{ Sexual performance } \\
\hline Worse & $230(7.7)$ \\
\hline No change & 1852 (61.7) \\
\hline Better & 918 (30.6) \\
\hline \multicolumn{2}{|l|}{ Mood } \\
\hline Worse & $208(6.9)$ \\
\hline No change & $1529(51.0)$ \\
\hline Better & $1263(42.1)$ \\
\hline \multicolumn{2}{|l|}{ Memory } \\
\hline Worse & $193(6.4)$ \\
\hline No change & $1574(52.5)$ \\
\hline Better & $1233(41.1)$ \\
\hline \multicolumn{2}{|l|}{ Quality of sleep } \\
\hline Worse & $183(6.1)$ \\
\hline No change & 1398 (46.6) \\
\hline Better & 1419 (47.3) \\
\hline \multicolumn{2}{|l|}{ Endurance } \\
\hline Worse & $224(7.5)$ \\
\hline No change & $1325(44.2)$ \\
\hline Better & $1451(48.4)$ \\
\hline
\end{tabular}




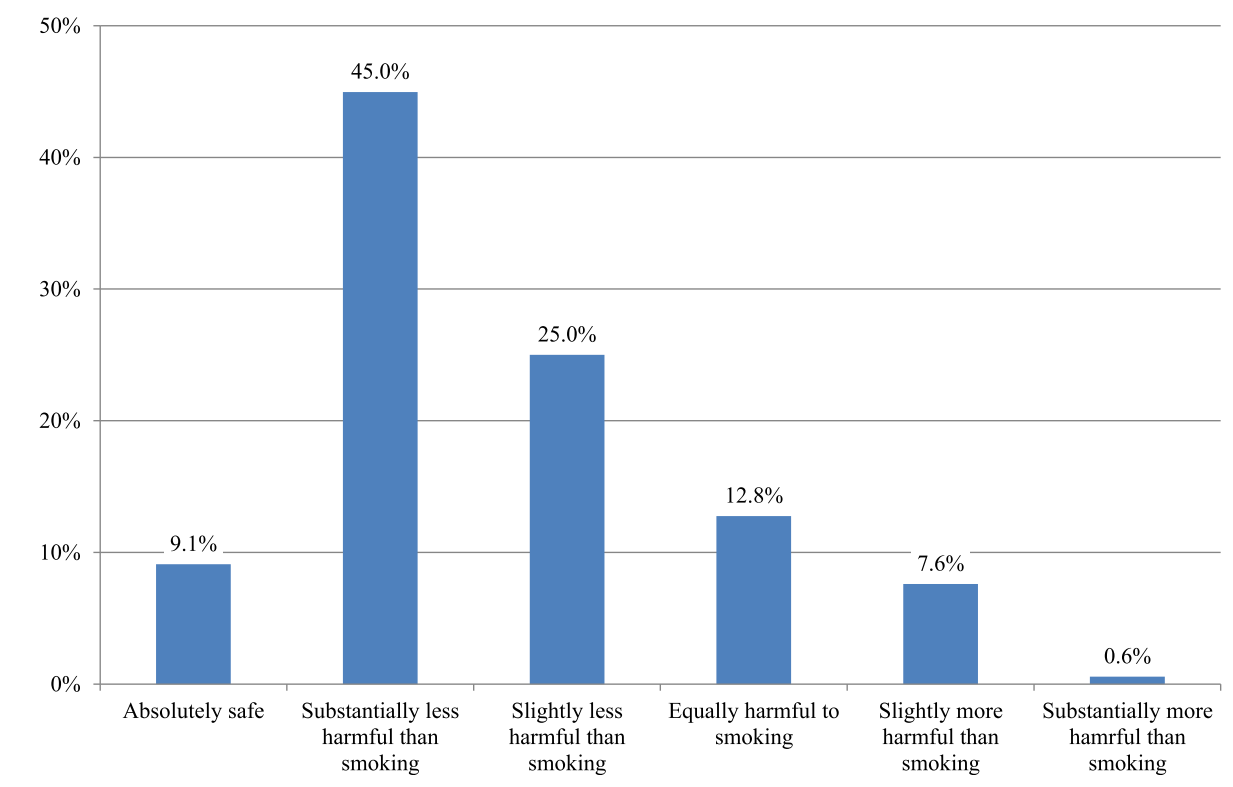

Fig. 2 Perception of harm about e-cigarettes

order to successfully substitute for smoking [22, 32], and it is expected that tobacco users would need high enough amounts to satisfy their nicotine cravings. While nicotine use by never smokers carries a risk of dependence, it is important for smokers to use e-cigarettes with sufficient nicotine delivery. Another factor that affects nicotine delivery is the type of device used. A large proportion of vapers in this study initiated e-cigarette use with first generation devices, and many were still using them at the time of the survey. These devices are known to deliver a limited amount of nicotine compared to more advanced products [33-35]. This may be due to India being a small and developing market for these products, with lack of information to guide choice of devices compared to other countries where e-cigarettes have been available more widely and for a longer time. Finally, perceiving e-cigarettes as less harmful than smoking was associated with being a former smoker, in agreement with a previous study [36]. While it is expected that smokers need to trust any alternative-tosmoking product in order to succeed in quitting, it is unclear whether the perceptions observed herein were the reason for, or the result of, quitting smoking.

Less than $35 \%$ of participants experienced some selfreported side effects after e-cigarette use initiation. The most common were cough and dry mouth and throat. These have been observed in previous studies too [22, 37,38 ] and are commonly attributed to the humectant and irritating effects of propylene glycol and glycerol. At the same time, they perceived significant benefits in physiologic functions, mainly breathing and olfactory and gustatory senses, and overall physical status were reported. Obviously, the convenience sampling design of this study is an important limitation; thus, the findings should be interpreted with caution and may not be representative of the experience of all people who try and use e-cigarettes. Still, the findings are consistent with limited clinical studies showing benefits among smokers who switch to e-cigarettes [39, 40].

India has the second lowest quit rate among GATS-2 countries surveyed at the end of 2017 [6]. Despite a large proportion of smokers reporting a desire to quit, few make a quit attempt each year, and a small minority achieve abstinence $[1,41]$. GATS- 2 data for India show that only $50-55 \%$ of tobacco users intended, and about $39 \%$ attempted, to quit [42]. Obviously, a much smaller proportion is successful in quitting. Lung cancer, the most prevalent type of cancer today [43], is highly prevalent in India. It is the most prevalent cancer among males, and the seventh most prevalent among females [44], which correlates well with the differential tobacco smoking prevalence among males and females [6]. The most recent demographic data indicate that the recorded decline in tobacco usage in India noted in the intervening 7 years between GATS-1 and GATS- 2 is probably insufficient to strongly reduce the prevalence of disease associated with tobacco use. Both smoking and SLT use continue to be a serious public health concern in India. Currently, available tobacco cessation services are inadequate to care for the estimated 267 million tobacco users, including over 100 million smokers $[6,11]$. This lack of capacity is compounded by a lack of capability among healthcare professionals, who are mostly inadequately trained, to deliver tobacco cessation advice. The 
Table 7 Regression analysis to identify correlates of having quit smoking

\begin{tabular}{|c|c|c|}
\hline & \multicolumn{2}{|c|}{ Odds of being a former smoker } \\
\hline & $\mathrm{OR}(95 \% \mathrm{Cl})$ & $P$ value \\
\hline Age & $1.00(0.98-1.01)$ & 0.573 \\
\hline \multicolumn{3}{|l|}{ Gender } \\
\hline \multicolumn{3}{|l|}{ Female (point of reference) } \\
\hline Male & $0.58(0.43-0.80)$ & 0.001 \\
\hline \multicolumn{3}{|l|}{ Education } \\
\hline \multicolumn{3}{|c|}{ Less than Senior School Certificate (point of reference) } \\
\hline Secondary/High School Certificate & $1.95(0.21-18.31)$ & 0.560 \\
\hline Graduate/postgraduate & $3.07(0.33-28.20)$ & 0.322 \\
\hline Professional degree & $4.38(0.48-40.31)$ & 0.192 \\
\hline Smoking duration & $1.00(1.00-1.00)$ & 0.399 \\
\hline Smoking before e-cigarette use initiation & $1.03(0.99-1.07)$ & 0.156 \\
\hline FTCD & $0.86(0.81-0.92)$ & $<0.001$ \\
\hline E-cigarette use duration & $0.99(0.98-1.00)$ & 0.017 \\
\hline \multicolumn{3}{|l|}{ E-cigarette use frequency } \\
\hline \multicolumn{3}{|l|}{ Less than monthly (point of reference) } \\
\hline Daily & $2.67(1.28-5.58)$ & 0.009 \\
\hline Weekly & $3.04(1.45-6.38)$ & 0.003 \\
\hline Monthly & $1.70(0.76-3.81)$ & 0.199 \\
\hline E-cigarette liquid consumption & $1.33(1.27-1.39)$ & $<0.001$ \\
\hline Nicotine concentration & $1.06(1.02-1.10)$ & 0.007 \\
\hline \multicolumn{3}{|l|}{ Number of flavors used } \\
\hline \multicolumn{3}{|l|}{1 (point of reference) } \\
\hline 2 or more & $1.25(0.99-1.57)$ & 0.062 \\
\hline \multicolumn{3}{|l|}{ Flavors type used } \\
\hline \multicolumn{3}{|c|}{ Tobacco/mint/menthol only (point of reference) } \\
\hline At least one non-tobacco/mint/menthol & $0.95(0.76-1.19)$ & 0.669 \\
\hline \multicolumn{3}{|l|}{ Perception of harm } \\
\hline \multicolumn{3}{|c|}{ Equally/more harmful than smoking (point of reference) } \\
\hline Harmless/less harmful than smoking & $1.80(1.34-2.41)$ & $<0.001$ \\
\hline
\end{tabular}

FTCD Fagerstrom Test for Cigarette Dependence

use of tobacco by healthcare professionals is also prevalent, potentially demotivating provision of effective cessation advice to smokers [10]. The existing tobacco control program needs to be strengthened by including additional tobacco cessation aids. The present study suggests that there is a potential for e-cigarettes to substitute for smoking and SLT use among Indian tobacco users. Clinical trial evidence is emerging supporting the smoking cessation efficacy of e-cigarettes [17]. On the other hand, the Indian government has recently banned ecigarette sale due to concerns that they are not risk-free and that their availability could trigger use by never smokers and youth, among others. To benefit public health, a balance is needed between encouraging smokers who are unable or unwilling to quit with approved methods to use e-cigarettes as smoking cessation aids and preventing its use by non-smokers. Regulations that achieve this balance do exist, for example in Europe, where e-cigarettes are regulated through the Tobacco Products Directive as consumer products with specific restrictions [45]. It is unlikely that the implemented ban in India represents a balanced approach, especially when considering that there has been no research on the profile of Indian vapers, their tobacco use profile before and after e-cigarette use initiation, and how the ban will affect their future tobacco use. While one of the main reasons behind the ban is to prevent youth use, to the best of our knowledge and belief, no study has examined use of e-cigarettes among Indian youth. Youth use in other countries has been largely experimental and confined to youth who 
were already smoking or had tried tobacco cigarettes in the past $[46,47]$. Other issues, such as the development of a black market with uncontrolled product quality, have not been considered either. This study provides preliminary insight into the use of e-cigarettes by Indian vapers, but research should be expanded by examining population-representative samples and assessing the impact of the ban at a population level.

A limitation of this study is the convenience sampling design, which cannot ensure that the profile of the vapers examined represent the average Indian consumer. Still, this remains the first study examining patterns of e-cigarette use in India. Additionally, the tobacco use status of participants was self-reported and not objectively verified, although this is common for large surveys. Data on tobacco use patterns and dependence before ecigarette use initiation were accessed retrospectively, and there is a possibility for recall bias. Finally, despite participants responding on whether e-cigarettes helped them quit or reduce tobacco use, this is a cross-sectional study, and causal relationships cannot be confirmed. Future prospective or longitudinal studies are needed to confirm the suggested result.

\section{Conclusion}

In conclusion, and considering the above-mentioned limitations, Indian e-cigarette users who participated in the study were predominantly smokers and SLT users, with a significant proportion of them managing to quit or reduce their tobacco consumption. Minimal side effects were experienced, while some health benefits were also reported. Our findings highlight the potential of ecigarettes to be an additional option for tobacco control. This may be especially relevant for countries such as India, which have (a) high tobacco-related health burden, (b) complex tobacco landscape, and (c) inadequate infrastructure and resources for offering tobacco cessation to help smokers and SLT users quit. While the opportunity for India seems to have been missed due to the implemented ban, public health authorities should encourage additional research and consider suitable modifications in the regulatory framework if findings support such a need.

\section{Abbreviations}

SLT: Smokeless tobacco; E-cigarette: Electronic cigarette; WHO: World Health Organization; GATS: Global Adult Tobacco Survey; IQR: Interquartile range

\section{Acknowledgements}

No grant from any public, commercial, or not-for-profit agency was received for this study. Authors gratefully acknowledge all infrastructure support of their parent institutions for conduct of this research and constructive comments on the manuscript from Dr. G. Stimson, London.

\section{Authors' contributions}

RNS and FS: study concept and design, questionnaire (design, testing, and validation), and interpretations; RNS and TMC: conduct of the research, analysis of data, data interpretations, and preparation of the manuscript; and RNS and TKS: statistical analysis of the data and its interpretations. The authors read and approved the final manuscript.

\section{Funding}

No specific funding was received for this study.

Availability of data and materials

Most data are contained in the manuscript itself. Additional information, if required, shall be made available.

\section{Ethics approval and consent to participate}

Institutional Ethics Committee for Human Samples/Participants (IECHSP) of NEHU provided approval to conduct this research vide clearance certificate issued on 2nd August 2017.

\section{Consent for publication}

All authors agree with the content of this manuscript and have given consent for publication.

\section{Competing interests}

None of the authors declare any competing interest.

\section{Author details}

${ }^{1}$ Radiation \& Molecular Biology Unit, Department of Biochemistry, North-Eastern Hill University, Shillong 793022, India. ${ }^{2}$ Department of Statistics, North-Eastern Hill University, Shillong 793022, India. ${ }^{3}$ Department of Cardiology, Onassis Cardiac Surgery Center, Sygrou 356, 17674 Kallithea, Greece. ${ }^{4}$ Center of Excellence in Trauma and Accidents, King Abdulaziz University, Jeddah, Saudi Arabia. ${ }^{5}$ Department of Pharmacy, University of Patras, 26500 Rio, Greece.

Received: 17 July 2019 Accepted: 13 March 2020

Published online: 30 March 2020

\section{References}

1. Abrams DB, Glasser AM, Pearson JL, Villanti AC, Collins LK, Niaura RS. Harm minimization and tobacco control: reframing societal views of nicotine use to rapidly save lives. Ann. Rev. Public Health. 2018;39:193-213.

2. WHO-GHO. World Health Organization Global Health Observatory (GHO) data. Prevalence of tobacco smoking. 2018; Available at: http://www.who. int/gho/tobacco/use/en/ (accessed on 18 Dec 2019).

3. Sharan RN, Mehrotra R, Choudhury $Y$, Asotra K. Association of betel nut with carcinogenesis: revisit with a clinical perspective. PLoS One. 2012;7(8): e42759. https://doi.org/10.1371/journal.pone.0042759.

4. Chandrupatla SG, Tavares M, Natto ZS. Tobacco use and effects of professional advice on smoking cessation among youth in India. Asian Pac. J. Cancer Prev. 2017:18(7):1861-7. https://doi.org/10.22034/APJCP.2017.18.7.1861.

5. Murray CJ, Lopez AD. The global burden of disease: a comprehensive assessment of mortality and disability from diseases, injuries and risk factors in 1990 and projected to 2020. Cambridge, MA: Harvard School of Public Health. 1996;274(5288):740-743.

6. Asma S, Mackay J, Song SY, Zhao L, Morton J, Palipudi KM. The GATS Atlas. 2015. Atlanta, GA: CDC Foundation; 2018. http://gatsatlas.org/\# (accessed online on 18 Dec 2018).

7. Dandona L, Dandona R, Kumar GA, Shukla DK, Paul VK, Balakrishnan K, Prabhakaran D, Tandon N, Salvi S, Dash AP, Nandakumar A. Nations within a nation: variations in epidemiological transition across the states of India, 1990-2016 in the Global Burden of Disease Study. Lancet. 2017;390(10111): 2437-60. https://doi.org/10.1016/S0140-6736(17)32861-1.

8. Morgan AD, Zakeri R, Quint JK. Defining the relationship between COPD and CVD: what are the implications for clinical practice? Ther. Adv Respir. Dis. 2018;12:1753465817750524. https://doi.org/10.1177/1753465817750524.

9. Roversi S, Fabbri LM, Sin DD, Hawkins NM, Agusti A. Chronic obstructive pulmonary disease and cardiac diseases. An urgent need for integrated care. Am. J. Respir. Crit. Care Med. 2016;194(11):1319-36.

10. Thankappan KR. Tobacco cessation in India: a priority health intervention. Indian J Med Res. 2014;139(4):484-6.

11. Varghese C, Kaur J, Desai NG, et al. Initiating tobacco cessation services in India: challenges and opportunities. WHO South East Asia J Public Health. 2012;1(2):159-68. 
12. McKay AJ, Patel RKK, Majeed A. Strategies for tobacco control in India: a systematic review. PLoS ONE. 2015;10(4):e0122610.

13. Murthy $P$, Saddichha S. Tobacco cessation services in India: recent developments and the need for expansion. Indian J Cancer. 2010;47(Suppl 1):69-74.

14. Newton JN, Dockrell M, Marczylo T. Making sense of the latest evidence on electronic cigarettes. Lancet. 2018;391(10121):639-42.

15. Das S, Choudhury Y, Vaiphei ST, Sharan RN. A systematic review and metaanalysis on the health and safety implications of electronic nicotine delivery systems (ENDS). Indian J. Clin. Practice. 2019;29(11):1016-26.

16. Farsalinos K, Russell C, Sharan R. E-cigarettes in India: overview of evidence, opportunities and challenges based on experience in Western countries. Indian J. Clin. Practice. 2019;29(12):1106-20.

17. Hajek P, Phillips-Waller A, Przulj D, Pesola F, Myers Smith K, Bisal N, Li J, Parrott S, Sasieni P, Dawkins L, Ross L, Goniewicz M, Wu Q, McRobbie HJ. A Randomized trial of e-cigarettes versus nicotine-replacement therapy. $\mathrm{N}$ Engl J Med. 2019;380:629-37. https://doi.org/10.1056/NEJMoa1808779.

18. Farsalinos KE, Polosa R. Safety evaluation and risk assessment of electronic cigarettes as tobacco cigarette substitutes: a systematic review. Ther Adv Drug Saf. 2014 Apr;5(2):67-86. https://doi.org/10.1177/2042098614524430.

19. Farsalinos K. Electronic cigarettes: an aid in smoking cessation, or a new health hazard? Ther. Adv. Respir. Dis. 2018;12:1753465817744960.

20. Indian Council of Medical Research. White paper on electronic nicotine delivery system. Indian J Med Res. 2019. https://doi.org/10.4103/ijmr.IJMR_ 957_19.

21. Farsalinos K, Ambekar A, Polosa R. White paper on electronic nicotine delivery systems by the Indian Council of Medical Research: a critical appraisal of the scientific evidence. Indian J Clin Practice. 2019;30(3):214-24.

22. Farsalinos K, Romagna G, Tsiapras D, Kyrzopoulos S, Voudris V. Characteristics, perceived side effects and benefits of electronic cigarette use: a worldwide survey of more than 19,000 consumers. Int. J. Environ. Res. Public Health. 2014;11(4):4356-73. https://doi.org/10.3390/ijerph110404356.

23. Farsalinos K, Romagna G, Tsiapras D, Kyrzopoulos S, Spyrou A, Voudris V. Impact of flavour variability on electronic cigarette use experience: an internet survey. Int. J. Environ. Res. Public Health. 2013;10(12):7272-82. https://doi.org/10.3390/ijerph10127272.

24. Collins D. Pretesting survey instruments: an overview of cognitive methods. Qual. Life Res. 2003:12(3):229-38.

25. Fagerström K. Determinants of tobacco use and renaming the FTND to the Fagerstrom Test for Cigarette Dependence. Nicotine Tob. Res. 2012;14:75-8. https://doi.org/10.1093/ntr/ntr137.

26. Farsalinos KE, Siakas G, Poulas K, Voudris V, Merakou K, Barbouni A Electronic cigarette use in Greece: an analysis of a representative population sample in Attica prefecture. Harm Reduct J. 2018 Apr 13;15(1):20. https://doi. org/10.1186/s12954-018-0229-7.

27. Farsalinos KE, Poulas K, Voudris V, Le Houezec J. Prevalence and correlates of current daily use of electronic cigarettes in the European Union: analysis of the 2014 Eurobarometer survey. Intern Emerg Med. 2017 Sep;12(6):75763. https://doi.org/10.1007/s11739-017-1643-7.

28. Biener L, Hargraves JL. A longitudinal study of electronic cigarette use among a population-based sample of adult smokers: association with smoking cessation and motivation to quit. Nicotine Tob Res. 2015;17:127-33.

29. Levy DT, Yuan Z, Luo Y, Abrams DB. The relationship of e-cigarette use to cigarette quit attempts and cessation: insights from a large, nationally representative U.S. survey. Nicotine Tob Res. 2018;20:931-9.

30. Brose LS, Hitchman SC, Brown J, West R, McNeill A. Is the use of electronic cigarettes while smoking associated with smoking cessation attempts, cessation and reduced cigarette consumption? A survey with a 1-year follow-up. Addiction. 2015;110:1160-8.

31. Farsalinos K, Niaura R. E-cigarettes and smoking cessation in the United States according to frequency of e-cigarette use and quitting duration: analysis of the 2016 and 2017 National Health Interview Surveys. Nicotine Tob Res. 2019. https://doi.org/10.1093/ntr/ntz025.

32. Farsalinos KE, Romagna G, Tsiapras D, Kyrzopoulos S, Voudris V. Evaluating nicotine levels selection and patterns of electronic cigarette use in a group of "vapers" who had achieved complete substitution of smoking. Subst Abuse. 2013;7:139-46.

33. Yingst JM, Foulds J, Veldheer S, Hrabovsky S, Trushin N, Eissenberg TT, Williams J, Richie JP, Nichols TT, Wilson SJ, Hobkirk AL. Nicotine absorption during electronic cigarette use among regular users. PLoS One. 2019;14(7): e0220300. https://doi.org/10.1371/journal.pone.0220300.
34. Farsalinos KE, Spyrou A, Tsimopoulou K, Stefopoulos C, Romagna G, Voudris V. Nicotine absorption from electronic cigarette use: comparison between first and new-generation devices. Sci Rep. 2014;4:4133. https://doi.org/10. 1038/srep04133.

35. Nides MA, Leischow SJ, Bhatter M, Simmons M. Nicotine blood levels and short-term smoking reduction with an electronic nicotine delivery system. Am J Health Behav. 2014;38(2):265-74. https://doi.org/10.5993/AJHB.38.2.12.

36. Farsalinos KE, Romagna G, Voudris V. Factors associated with dual use of tobacco and electronic cigarettes: a case control study. Int J Drug Policy. 2015;26(6):595-600. https://doi.org/10.1016/j.drugpo.2015.01.006.

37. Dawkins L, Turner J, Roberts A, Soar K. 'Vaping' profiles and preferences: an online survey of electronic cigarette users. Addiction. 2013;108:1115-25.

38. Etter JF, Bullen C. Electronic cigarette: users profile, utilization, satisfaction and perceived efficacy. Addiction. 2011;106:2017-1028.

39. George J, Hussain M, Vadiveloo T, Ireland S, Hopkinson P, Struthers AD, Donnan PT, Khan F, Lang CC. Cardiovascular effects of switching from tobacco cigarettes to electronic cigarettes. J Am Coll Cardiol. 2019;74(25): 3112-20. https://doi.org/10.1016/j.jacc.2019.09.067.

40. Polosa R, Morjaria JB, Caponnetto P, Caruso M, Campagna D, Amaradio MD, Ciampi G, Russo C, Fisichella A. Persisting long term benefits of smoking abstinence and reduction in asthmatic smokers who have switched to electronic cigarettes. Discov Med. 2016;21:99-108.

41. MMWR (2000) Reducing tobacco use: a report of the Surgeon General executive summary. MMWR Recomm Rep., 22, 49 (RR-16), 1-27 2000; (https://www.cdc.gov/mmwr/preview/mmwrhtml/rr4916a1.htm).

42. TISS. Global Adult Tobacco Survey GATS 2 India 2016-17 $-2^{\text {nd }}$ Round. Published by Tata Institute of Social Sciences, Mumbai and MHFW, Government of India. 2018 Available at: http://www.searo.who.int/entity/ ncd_tobacco_surveillance/documents/ind_gats_report_2016-17.pdf?ua=1 (accessed on 18 Dec 2019).

43. WHO. Latest global cancer data: cancer burden rises to 18.1 million new cases and 9.6 million cancer deaths in 2018. World Health Organization Press Release \# 263 of $12^{\text {th }}$ September 2018. 2018; (https://www.who.int/ cancer/PRGlobocanFinal.pdf).

44. Dhillon PK, Mathur P, Nandakumar A, Fitzmaurice C, Kumar GA, Mehrotra R, Shukla DK, Rath GK, Gupta PC, Swaminathan R, Thakur JS. The burden of cancers and their variations across the states of India: the Global Burden of Disease Study 1990-2016. Lancet Oncol. 2018;19(10):1289-306. https://doi. org/10.1016/S1470-2045(18)30447-9.

45. Directive 2014/40/EU of the European Parliament and of the Council of 3 April 2014 on the approximation of the laws, regulations and administrative provisions of the Member States concerning the manufacture, presentation and sale of tobacco and related products and repealing Directive 2001/37/ EC. Available from: http://eur-lex.europa.eu/legal-content/en/TXT/?uri= CELEX\%3A32014L0040 (accessed on 10 Dec 2019).

46. Glasser AM, Johnson AL, Niaura RS, Abrams DB, Pearson JL. Youth vaping and tobacco use in context in the United States: results from the 2018 National Youth Tobacco Survey. Nicotine Tob Res. 2020. https://doi.org/10. 1093/ntr/ntaa010.

47. Farsalinos K, Tomaselli V, Polosa R. Frequency of use and smoking status of U.S. Adolescent E-Cigarette Users in 2015. Am J Prev Med. 2018;54(6):81420. https://doi.org/10.1016/j.amepre.2018.03.003.

\section{Publisher's Note}

Springer Nature remains neutral with regard to jurisdictional claims in published maps and institutional affiliations.

\section{Ready to submit your research? Choose BMC and benefit from:}

- fast, convenient online submission

- thorough peer review by experienced researchers in your field

- rapid publication on acceptance

- support for research data, including large and complex data types

- gold Open Access which fosters wider collaboration and increased citations

- maximum visibility for your research: over $100 \mathrm{M}$ website views per year

At $\mathrm{BMC}$, research is always in progress.

Learn more biomedcentral.com/submissions 